\title{
Prognostic significance of the epithelial-mesenchymal transition factor zinc finger E-box-binding homeobox 2 in esophageal squamous cell carcinoma
}

\author{
XIAODONG HUO ${ }^{1,2}$, BIN HUO $^{2}$, HUIXING WANG $^{3}$, HONGDIAN ZHANG $^{1}$, \\ ZHAO MA ${ }^{1}$, MINGJIAN YANG ${ }^{1}$, HAITAO WANG $^{2}$ and ZHENTAO YU ${ }^{1}$ \\ ${ }^{1}$ Department of Esophageal Cancer, Tianjin Medical University Cancer Institute and Hospital, \\ Key Laboratory of Cancer Prevention and Therapy of Tianjin, Tianjin 300060; ${ }^{2}$ Department of Oncology; \\ ${ }^{3}$ Pain Management Center, Second Hospital of Tianjin Medical University, Tianjin 300211, P.R. China
}

Received February 21, 2016; Accepted April 25, 2017

DOI: $10.3892 / 01.2017 .6559$

\begin{abstract}
Zinc finger E-box-binding homeobox 2 (ZEB2) has been reported to mediate epithelial-mesenchymal transition (EMT) and disease progression in several cancer types. However, the expression of ZEB2 in esophageal squamous cell carcinoma (OSCC) and its association with prognosis remains unclear. In the present study, a tissue microarray and immunohistochemistry were used to investigate ZEB2 and epithelial (E-)cadherin expression in OSCC tissues $(n=218)$ and peritumoral esophageal tissues (POT; $n=60$ ). There was a significantly increased incidence of positive ZEB2 expression in OSCC tissues compared with the expression in POTs $(\mathrm{P}<0.012)$. By contrast, the incidence of positive E-cadherin expression in OSCC tissues was significantly decreased compared with the expression in POTs $(\mathrm{P}<0.004)$. ZEB2 expression in OSCC was associated with a number of clinicopathological factors, and it was also an independent predictive factor for shorter overall survival time $(\mathrm{P}<0.001)$. Overall, ZEB2 may promote OSCC metastasis and is a potential prognostic marker for malignancy.
\end{abstract}

\section{Introduction}

Although notable advances have been made in the prevention, diagnosis and treatment of cancer, esophageal squamous cell carcinoma (OSCC) remains a significant global health burden, particularly in China, where $\sim 70 \%$ of esophageal cancer is

Correspondence to: Dr Zhentao Yu, Department of Esophageal Cancer, Tianjin Medical University Cancer Institute and Hospital, Key Laboratory of Cancer Prevention and Therapy of Tianjin, 1 Huanhu West Road, Tianjin 300060, P.R. China

E-mail:yuzhtao@hotmail.com

Key words: epithelial-mesenchymal transition, zinc finger E-boxbinding homeobox 2, epithelial cadherin, esophageal squamous cell carcinoma
OSCC (1). OSCC is an aggressive cancer and the fourth most common cause of cancer-associated mortalities $(2,3)$. The progression of esophageal cancer is rapid, and there is a poor associated prognosis, with a 5-year overall survival rate of $10-42 \%$ (4-6). The association between genetic changes and clinical characteristics can reflect the biological events that promote OSCC invasion and metastasis, and the former may act as molecular tumor markers for diagnosis and prognosis. The principal driver of metastasis and invasion is epithelial-mesenchymal transition (EMT). Therefore, EMT-associated proteins are potentially useful diagnostic markers and therapeutic targets (7). The activation of EMT promotes tumor epithelial cells to dedifferentiate to a mesenchymal phenotype (8), during which cells gain the ability to penetrate the basement membrane and move to regional lymph nodes or distant organs (8). EMT-associated proteins have an important role in tumor progression, and a number of proteins are significantly associated with clinicopathological indexes (9). However, the EMT signalling network is extremely complex, and an improved understanding of the role that EMT-associated proteins have in this process may yield clinically useful information.

EMT, as demonstrated by the expression of EMT-associated proteins, has been reported in a number of different cancer types, including OSCC (10-12). Loss of epithelial (E-)cadherin expression and overexpression of zinc finger protein SNAI1, twist-related protein 1, testican-1, and receptor of activated protein kinase $\mathrm{C} 1$ has been reported to occur at the invasive front of OSCC, particularly in single or cords of tumor cells detaching from the main tumor mass (13-18). Although the expression of these EMT drivers have been well-researched in other cancer types, relatively little is known of their expression in OSCC (19).

Zinc finger E-box-binding homeobox 2 (ZEB2) is a transcription factor that can bind Smad proteins and contains multiple functional domains that interact with a variety of transcriptional co-effectors (20). ZEB2 directly binds adjacent E-boxes within the E-cadherin gene promoter and regulates transcriptional repression by recruiting corepressor complexes (21).

In the present study, immunohistochemistry (IHC) was performed to investigate the expression of the EMT-associated transcription factor ZEB2 and the cell adhesion protein 
E-cadherin in OSCC. It was observed that there were significant differences in the expression of ZEB2 and E-cadherin between OSCC and normal esophageal mucosa epithelial membrane, and multivariate analysis indicated that ZEB2 expression was an independent prognostic marker in OSCC.

\section{Materials and methods}

Patients and tumor samples. All tissues were obtained from patients with OSCC (183 males and 35 females) who underwent esophagostomy without any preoperative therapy at the Department of Esophageal Oncology, Cancer Hospital of Tianjin Medical University (Tianjin, China), between June 2006 and June 2009. Histopathological diagnosis was determined according to the National Comprehensive Cancer Network (NCCN) guidelines (22). Informed consent was obtained from all patients, and ethical approval was obtained from the Institutional Review Board of the Cancer Hospital of Tianjin Medical University.

Antibodies. A mouse anti-human monoclonal antibody against E-cadherin was purchased from Santa Cruz Biotechnology, Inc. (Dallas, TX, USA), and a rabbit anti-human polyclonal antibody against ZEB2 was obtained from Abcam (Cambridge, UK). The secondary antibodies were obtained from Shanghai Outdo Biotech Co., Ltd. (Shanghai, China).

Construction of tissue microarray (TMA). The thickness of the tissue section was $2 \mu \mathrm{m}$. The slides were evaluated by a senior pathologist to identify representative tumor areas. In brief, formalin-fixed, paraffin-embedded tissue blocks and the corresponding hematoxylin and eosin-stained slides were covered for TMA sampling. Multiple 0.6-mm diameter cylinders were punched from the representative tumor areas and from the adjacent peritumoral esophageal tissue using a tissue arrayer.

IHC. The TMA slides used an isotype control. The TMA slides were dried overnight at $37^{\circ} \mathrm{C}$, deparaffinized in xylene, rehydrated using a graded alcohol series and immersed in $3 \%$ hydrogen peroxide for 15 min to block endogenous peroxidase activity at $37^{\circ} \mathrm{C}$. Antigen-retrieval was performed by heating to $100^{\circ} \mathrm{C}$ in a pressure cooker for $3 \mathrm{~min}$ in EDTA buffer (pH 8.0). Subsequently, the slides were incubated with rabbit polyclonal anti-ZEB2 (dilution, 1:100; catalog no. ab138222) that recognized only a single band corresponding to ZEB2, or mouse anti-E-cadherin (dilution, 1:50; catalog no. sc-59778) for $16 \mathrm{~h}$ at $4^{\circ} \mathrm{C}$. The slides were subsequently incubated with a goat anti-rabbit immunoglobulin $\mathrm{G}$ conjugated to horseradish peroxidase (HRP) (dilution, 1:500; catalog no. abs20002A) for $1 \mathrm{~h}$ at $37^{\circ} \mathrm{C}$ and stained with 3,3-diaminobenzidine. Finally, the sections were counterstained with Mayer's hematoxylin, dehydrated and mounted. As a negative control, the primary antibody was replaced with KIT-9901 Elivision ${ }^{\mathrm{TM}}$ plus Polyer HRP (mouse/rabbit) IHC kit (Mai Xin Biotechnology Co., Ltd.). Patients with gastric cancer, from the Tianjin Medical University Cancer Institute and Hospital, which express ZEB2 were selected and used as a positive control.

Evaluation of IHC staining. All tissues were observed using a CX41 light microscope (Olympus Corporation, Tokyo,
Japan). All tissue sections were simultaneously assessed by two independent investigators, who were blinded to the patient clinicopathological details. The criteria for scoring ZEB2 and E-cadherin staining were as follows: Intensity was graded as 0 (negative), 1 (weak), 2 (moderate) or 3 (strong). The proportion of positive tumor cells was graded as $0(<5 \%), 1(5-25 \%), 2$ $(26-50 \%), 3(51-75 \%)$ or $4(>75 \%)$. A final score was derived by multiplying the two primary scores. Final scores of 0-4 were defined as negative expression (-), scores of 5-8 as weak positive expression ( + ) and scores of 9-12 as strong positive expression $(++)(23)$.

Statistical analysis. Statistical analyses were performed using SPSS software (version 17.0; SPSS Inc., Chicago, IL, USA). The $\chi^{2}$ test was used to assess associations between ZEB2, E-cadherin and various clinicopathological variables. All factors were examined using univariate analysis and significant factors were further examined using multivariate analysis. Survival was analyzed using the Kaplan-Meier estimator method. The statistical significance of the association between ZEB2 and E-cadherin expression and overall survival was estimated using the log rank test. Multivariate Cox's proportional hazards regression was used to identify independent factors for overall survival. $\mathrm{P}<0.05$ was considered to indicate a statistically significant difference from a two-tailed test.

\section{Results}

Patients and baseline characteristics. The study group comprised 183 males and 35 females, with a median age of 67.6 years (range, 39-99 years). All patients had undergone macroscopically curative resection, and none had received any preoperative chemotherapy or radiotherapy. Pathologically, all tumors were squamous cell carcinoma. A total of 2,834 lymph nodes were resected from 218 patients, with a median of 13.0 nodes per patient.

Expression of ZEB2 and E-cadherin in esophageal tissue. ZEB2 expression was observed in the cytoplasm of cancer cells. By contrast, E-cadherin expression was detected at the cell membrane (Fig. 1). IHC analysis identified positive ZEB2 expression in 77 tumors $(35.3 \%)$ and positive E-cadherin expression in 100 tumor s (45.9\%). ZEB2 expression was significantly different between OSCCs and POTs in the patients $\left(\chi^{2}=6.276 ; \mathrm{P}<0.05\right)$. Similar results were observed for E-cadherin expression $\left(\chi^{2}=8.139 ; \mathrm{P}<0.05\right)$ (Table I).

Association between ZEB2 and E-cadherin expression in OSCC and POT. E-cadherin membrane expression and a low level of ZEB2 expression were observed in normal esophageal epithelial tissues (Fig. 2). IHC analysis identified positive ZEB2 expression in 11 POT cases (18.3\%), and positive E-cadherin expression in 40 POT cases $(66.7 \%)$ (Table I). Negative E-cadherin staining was detected in 53/77 (68.8\%) cases positive for ZEB2 expression. Positive E-cadherin staining was detected in 76/141 (53.9\%) cases negative for ZEB2 expression. Therefore, the expression of ZEB2 and E-cadherin was significantly and inversely associated in OSCC $\left(\chi^{2}=10.365 ; \mathrm{P}<0.05\right)$ (Table II). Similarly, the 
Table I. Expression of ZEB2 and E-cadherin in esophageal tissue.

\begin{tabular}{|c|c|c|c|c|c|c|c|c|}
\hline \multirow{2}{*}{$\begin{array}{l}\text { Tumour } \\
\text { type }\end{array}$} & \multicolumn{2}{|c|}{ ZEB2, n } & \multirow[b]{2}{*}{$\chi^{2}$} & \multirow[b]{2}{*}{ P-value } & \multicolumn{2}{|c|}{ E-cadherin, $n$} & \multirow[b]{2}{*}{$\chi^{2}$} & \multirow[b]{2}{*}{ P-value } \\
\hline & - & + & & & - & + & & \\
\hline OSCC & 141 & 77 & 6.276 & $0.012^{\mathrm{a}}$ & 118 & 100 & 8.139 & $0.004^{\mathrm{b}}$ \\
\hline POT & 49 & 11 & & & 20 & 40 & & \\
\hline
\end{tabular}

${ }^{a}$ Expression of ZEB2 in OSCC vs. POT. ${ }^{b}$ Expression of E-cadherin in OSCC vs. POT. OSCC, esophageal squamous cell carcinoma; POT, peritumoral esophageal tissue; ZEB2, zinc finger E-box-binding homeobox 2; E-cadherin, epithelial cadherin.

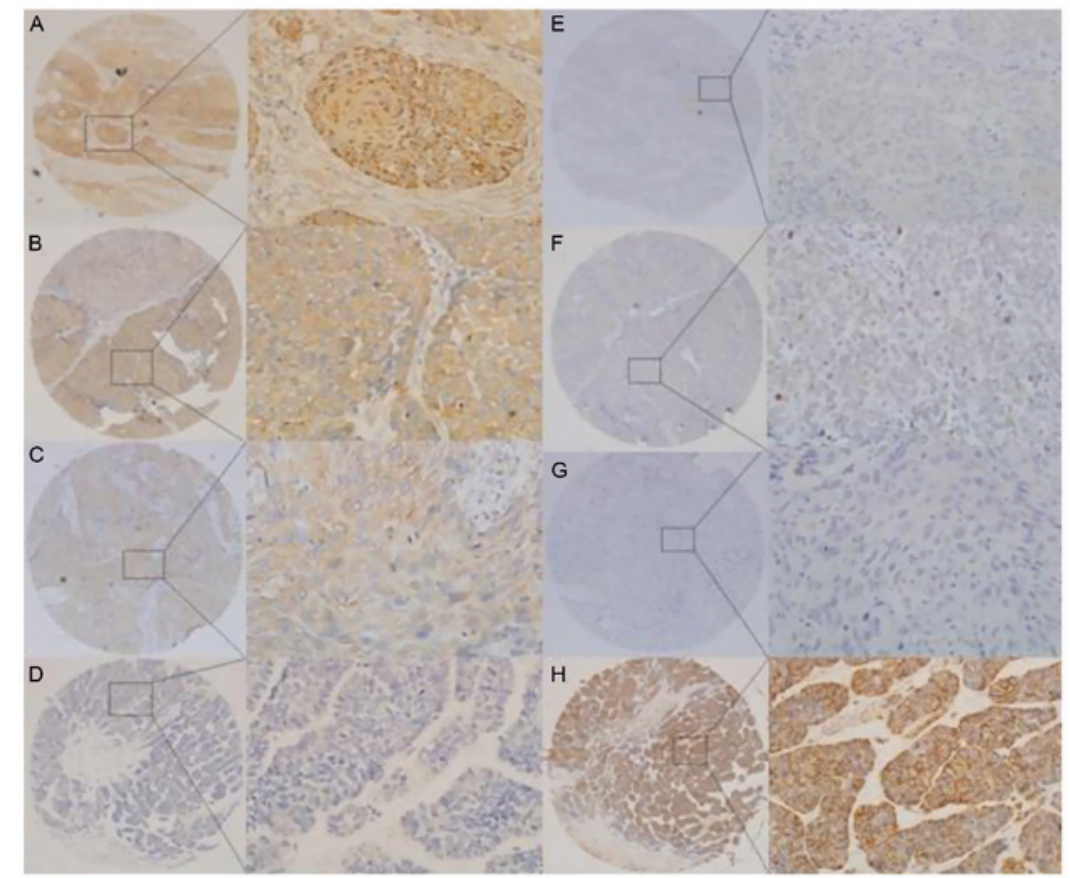

Figure 1. ZEB2 and E-cadherin expression in OSCC tissues. Representative tissues exhibiting (A) strong positive ZEB2 expression, (B) moderately positive ZEB2 expression, (C) weakly positive ZEB2 expression, (D) negative ZEB2 expression, (E-G), negative E-cadherin expression and (H) positive E-cadherin expression at the cell membrane. Magnification, x40 (left) and x400 (right). OSCC, esophageal squamous cell carcinoma; ZEB2, zinc finger E-box-binding homeobox 2; E-cadherin, epithelial cadherin.

Table II. Association between ZEB2 and E-cadherin immunoexpression in esophageal squamous cell carcinoma.

\begin{tabular}{lcccc}
\hline & \multicolumn{3}{c}{ ZEB2 expression } & \\
\cline { 2 - 4 } & $\begin{array}{c}\text { Positive } \\
(\mathrm{n}=77)\end{array}$ & $\begin{array}{c}\text { Negative } \\
(\mathrm{n}=141)\end{array}$ & $\chi^{2}$ & P-value \\
\hline $\begin{array}{l}\text { E-cadhmunohistochemistry-positive } \\
(\mathrm{n}=100)\end{array}$ & 24 & 76 & 10.365 & $0.001^{\mathrm{a}}$ \\
$\begin{array}{l}\text { E-cadherin-negative } \\
(\mathrm{n}=118)\end{array}$ & 53 & 65 & & \\
\end{tabular}

aZEB2 vs. E-cadherin immunoexpression in OSCC. ZEB2, zinc finger E-box-binding homeobox 2; E-cadherin, epithelial cadherin.

expression of ZEB2 and E-cadherin was significantly and inversely associated in POT $\left(\chi^{2}=4.219 ; \mathrm{P}<0.05\right)$ (Table III).
Table III. Association between ZEB2 and E-cadherin immunoexpression in peritumoral esophageal tissues.

\begin{tabular}{lcccc}
\hline & \multicolumn{2}{c}{ ZEB2 } & & \\
\cline { 2 - 4 } & $\begin{array}{c}\text { Positive } \\
(\mathrm{n}=11)\end{array}$ & $\begin{array}{c}\text { Negative } \\
(\mathrm{n}=49)\end{array}$ & $\chi^{2}$ & P-value \\
Immunohistochemistry & 5 & 35 & 4.219 & $0.040^{\mathrm{a}}$ \\
$\begin{array}{l}\text { E-cadherin-positive } \\
(\mathrm{n}=40)\end{array}$ & 7 & 13 & & \\
$\begin{array}{l}\text { E-cadherin-negative } \\
(\mathrm{n}=20)\end{array}$ & & & & \\
\hline
\end{tabular}

${ }^{a} Z E B 2$ vs. E-cadherin immunoexpression in POT. ZEB2, zinc finger E-box-binding homeobox 2; E-cadherin, epithelial cadherin.

Association between ZEB2 and E-cadherin expression and clinicopathological factors. Further analysis indicated that 


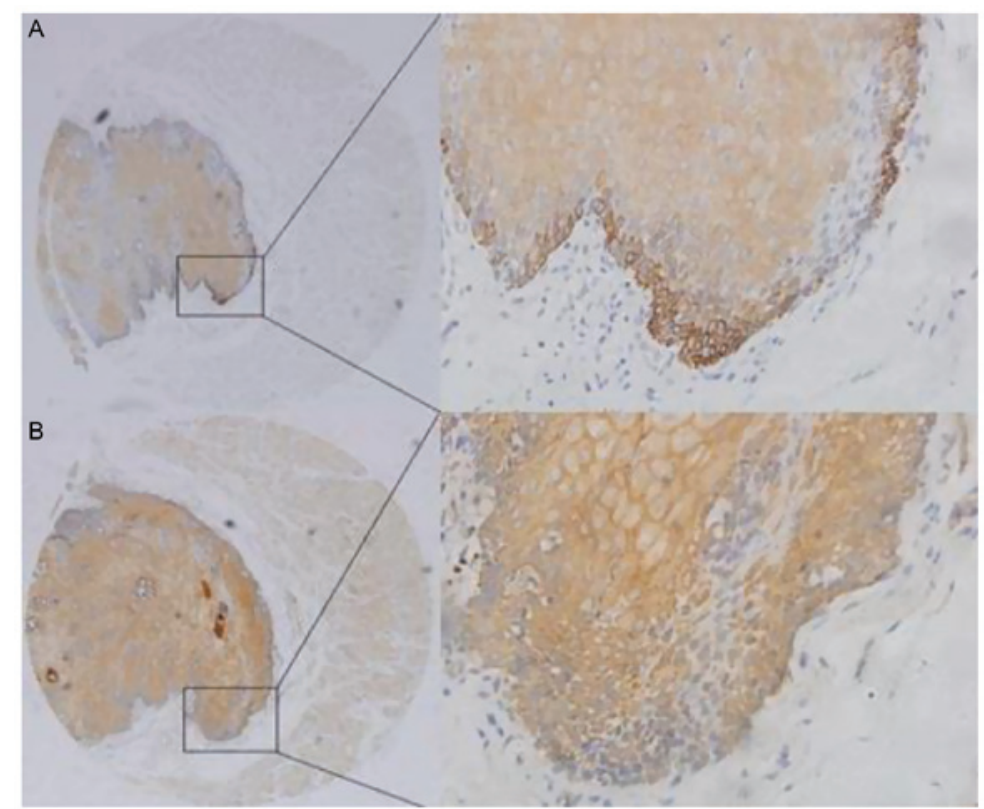

Figure 2. E-cadherin and ZEB2 expression in peritumoral esophageal tissues. Magnification, $x 40$ (left) and x400 (right). (A) E-cadherin expression was detected at the cell membrane of normal esophageal epithelial tissue. (B) A low level of ZEB-2 expression was identified in normal esophageal epithelial tissues. ZEB2, zinc finger E-box-binding homeobox 2; E-cadherin, epithelial cadherin.
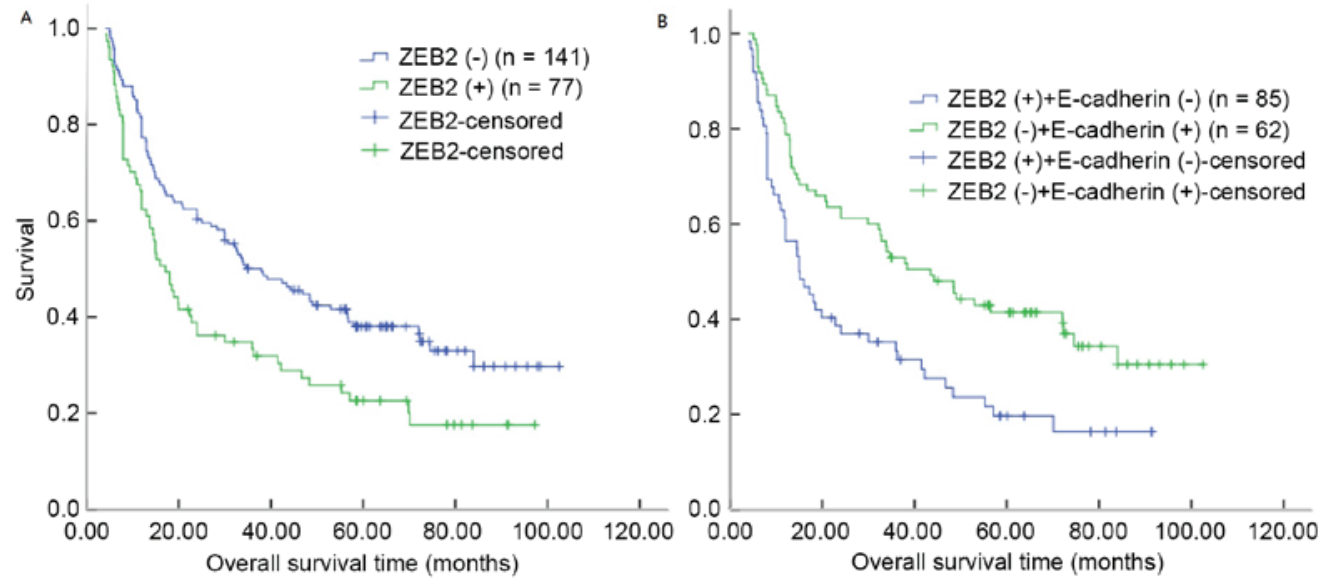

Figure 3. Prognosis and ZEB2 expression in patients with OSCC. (A) Kaplan-Meier analysis of overall survival rates for patients with OSCC and ZEB2 expression. (B) Kaplan-Meier analysis of overall survival rates for patients demonstrating different combinations of ZEB2 and E-cadherin expression. OSCC, esophageal squamous cell carcinoma; ZEB2, zinc finger E-box-binding homeobox 2; E-cadherin, epithelial cadherin.

the overexpression of ZEB2 in OSCC tissues was significantly associated with the depth of tumor invasion, lymph node metastasis and TNM stage $(\mathrm{P}<0.05$; Table IV). By contrast, negative expression of membrane E-cadherin was significantly associated with lymph node metastasis ( $\mathrm{P}=0.040$; Table IV). No significant associations were identified between expression of ZEB2 and clinicopathological variables, including sex, age, tumor position, tumor differentiation and tumor size ( $\mathrm{P}>0.05$; Table IV).

Prognostic significance of ZEB2 and E-cadherin expression. In OSCC tissue, univariate analyses revealed significant associations between overall survival and ZEB2 overexpression $(\mathrm{P}=0.002)$, tumor size $(\mathrm{P}=0.011)$, depth of tumor invasion $(\mathrm{P}=0.002)$, lymph node metastasis $(\mathrm{P}<0.0001)$ and TNM stage $(\mathrm{P}=0.004)$. By contrast, a lack of E-cadherin expression, poor differentiation, tumor site, age and sex were not significantly associated with prognosis (Table V). Kaplan-Meier analysis demonstrated that the median survival time for patients with ZEB2 overexpression in OSCC was 17.20 months, compared with 37.97 months for patients with OSCC and negative ZEB2 expression $(\mathrm{P}=0.003$, log-rank test; Table VI; Fig. 3A). However, the median survival time for patients with OSCC and E-cadherin membrane expression was 24.00 months, compared with 34.00 months for patients with OSCC and negative E-cadherin expression (log-rank test, $\mathrm{P}=0.055$; Table VI). Notably, patients with ZEB2 overexpression and negative E-cadherin expression demonstrated decreased overall survival times (log-rank test, $\mathrm{P}=0.002$; Fig. 3B).

Independent prognostic factors of OSCC. A multivariate analysis was performed to evaluate the variables that had 
Table IV. Clinicopathological features of esophageal squamous cell carcinoma and associations with ZEB2 and E-cadherin immunoexpression.

\begin{tabular}{|c|c|c|c|c|c|c|c|c|c|}
\hline \multirow[b]{2}{*}{ Variable } & \multirow[b]{2}{*}{ Total, $\mathrm{n}$} & \multicolumn{2}{|c|}{ ZEB2, n } & \multirow[b]{2}{*}{$\chi^{2}$} & \multirow[b]{2}{*}{ P-value } & \multicolumn{2}{|c|}{ E-cadherin, $\mathrm{n}$} & \multirow[b]{2}{*}{$\chi^{2}$} & \multirow[b]{2}{*}{ P-value } \\
\hline & & - & + & & & - & + & & \\
\hline Sex & & & & 0.020 & 0.889 & & & 1.279 & 0.258 \\
\hline Male & 183 & 118 & 65 & & & 96 & 87 & & \\
\hline Female & 35 & 23 & 12 & & & 22 & 13 & & \\
\hline Age, years & & & & 0.304 & 0.581 & & & 0.266 & 0.206 \\
\hline$<60$ & 47 & 32 & 15 & & & 27 & 20 & & \\
\hline$\geq 60$ & 171 & 109 & 62 & & & 91 & 80 & & \\
\hline Position & & & & 0.615 & 0.735 & & & 0.351 & 0.839 \\
\hline Upper & 11 & 6 & 5 & & & 5 & 6 & & \\
\hline Middle & 185 & 120 & 65 & & & 101 & 84 & & \\
\hline Lower & 22 & 15 & 7 & & & 12 & 10 & & \\
\hline Differentiation & & & & 2.998 & 0.223 & & & 4.058 & 0.131 \\
\hline Well & 58 & 31 & 27 & & & 24 & 34 & & \\
\hline Moderately & 71 & 39 & 32 & & & 29 & 42 & & \\
\hline Poorly & 56 & 38 & 18 & & & 32 & 24 & & \\
\hline Diameter, cm & & & & 3.792 & 0.052 & & & 0.914 & 0.339 \\
\hline$<4$ & 97 & 63 & 24 & & & 56 & 41 & & \\
\hline$\geq 4$ & 121 & 78 & 53 & & & 62 & 59 & & \\
\hline T status & & & & 4.104 & $0.043^{\mathrm{a}}$ & & & 0.759 & 0.384 \\
\hline $\mathrm{T} 1-\mathrm{T} 2$ & 38 & 30 & 8 & & & 23 & 15 & & \\
\hline $\mathrm{T} 3-\mathrm{T} 4$ & 180 & 111 & 69 & & & 95 & 85 & & \\
\hline $\mathrm{N}$ status & & & & 10.64 & $0.001^{\mathrm{a}}$ & & & 4.203 & $0.040^{\mathrm{a}}$ \\
\hline Negative & 131 & 96 & 35 & & & 58 & 63 & & \\
\hline Positive & 87 & 45 & 42 & & & 60 & 37 & & \\
\hline TNM stage (22) & & & & 11.08 & $0.001^{\mathrm{a}}$ & & & 0.390 & 0.533 \\
\hline I and II & 104 & 79 & 25 & & & 54 & 50 & & \\
\hline III & 114 & 62 & 52 & & & 64 & 50 & & \\
\hline Total & 218 & 141 & 77 & & & 118 & 100 & & \\
\hline
\end{tabular}

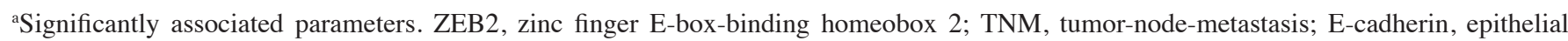
cadherin.

been identified to be significant in the univariate analysis. The analysis indicated that overexpression of ZEB2 was an independent prognostic factor for favorable overall survival among patients with OSCC (hazard ratio, 1.568; 95\% confidence interval, 1.084-2.269, $\mathrm{P}=0.017$; Table VI). Additionally, lymph node metastasis $(\mathrm{P}=0.001)$ was also identified to be an independent predictive factor for overall survival.

\section{Discussion}

Highly invasive and metastatic behavior underlies the aggressive nature of OSCC, which in turn depends on EMT (24). Although a number of proteins, including ZEB2, have been reported to serve key roles in EMT, not all the proteins have been demonstrated to have prognostic significance in OSCC (13-18,25-29). In the present study, ZEB2 expression was examined in a large number of samples taken from the invasive front of OSCC in order to assess its prognostic significance. The results indicate that ZEB2 is differentially expressed in OSCC and normal esophageal mucosal epithelium, and that ZEB2 expression is associated with shorter overall survival time (30).

Esophageal epithelial cells that have undergone EMT acquire functional characteristics of activated myofibroblasts in vitro (31). E-cadherin is a key component of adherence junctions that anchor esophageal epithelial cells (32). Loss of E-cadherin expression has been frequently reported in OSCC, particularly at the invasive tumor front (10) and is a recognized hallmark of EMT. The EMT phenotype can be controlled by the ZEB family of transcription factors, which is able to influence cell shape and adhesion, leading to an increased invasive potential (33). In the present study, ZEB2 was observed to be significantly overexpressed in $>35.3 \%$ of OSCC specimens. Consistent with the observations in the present study, ZEB2 has previously been reported to be overexpressed in several 
Table V. Univariate analyses of ZEB2 expression and clinicopathological variables in 218 patients with esophageal squamous cell carcinoma (log-rank tests).

\begin{tabular}{|c|c|c|c|c|c|}
\hline Variable & Total, $\mathrm{n}$ & $\begin{array}{l}\text { Median survival, } \\
\text { months }\end{array}$ & $\begin{array}{c}95 \% \text { confidence } \\
\text { interval }\end{array}$ & $\chi^{2}$ & P-value \\
\hline Sex & & & & 0.363 & 0.547 \\
\hline Male & 183 & 26.97 & $18.04-35.90$ & & \\
\hline Female & 35 & 34.00 & $20.38-45.39$ & & \\
\hline Age, years & & & & 1.963 & 0.136 \\
\hline$<60$ & 47 & 48.47 & $32.15-64.79$ & & \\
\hline$\geq 60$ & 171 & 24.00 & $15.99-32.01$ & & \\
\hline Position & & & & 3.137 & 0.208 \\
\hline Upper & 11 & 15.00 & $6.80-23.20$ & & \\
\hline Middle & 185 & 26.97 & $18.12-35.83$ & & \\
\hline Lower & 22 & 56.80 & $34.20-79.40$ & & \\
\hline Differentiation & & & & 4.049 & 0.129 \\
\hline Well & 58 & 35.46 & $23.46-48.55$ & & \\
\hline Moderately & 71 & 21.78 & $12.89-30.17$ & & \\
\hline Poorly & 56 & 18.95 & $9.74-25.67$ & & \\
\hline Diameter, cm & & & & 6.447 & $0.01^{\mathrm{a}}$ \\
\hline$<4$ & 97 & 36.00 & $20.19-51.81$ & & \\
\hline$\geq 4$ & 121 & 20.00 & $9.13-30.87$ & & \\
\hline T status (22) & & & & 9.781 & $0.002^{\mathrm{a}}$ \\
\hline $\mathrm{T} 1-\mathrm{T} 2$ & 38 & 70.10 & $45.89-94.31$ & & \\
\hline $\mathrm{T} 3-\mathrm{T} 4$ & 180 & 20.73 & $12.26-29.20$ & & \\
\hline $\mathrm{N}$ status (22) & & & & 17.722 & $0.000^{\mathrm{a}}$ \\
\hline Negative & 131 & 43.47 & $26.98-59.96$ & & \\
\hline Positive & 87 & 15.13 & $11.88-18.38$ & & \\
\hline${ }^{\mathrm{b}} \mathrm{TNM}$ stage & & & & 8.210 & $0.004^{\mathrm{a}}$ \\
\hline I and II & 104 & 43.47 & $23.95-62.99$ & & \\
\hline III & 114 & 18.10 & $13.01-23.19$ & & \\
\hline ZEB2 expression & & & & 9.095 & $0.002^{\mathrm{a}}$ \\
\hline Negative & 77 & 37.97 & $25.08-50.86$ & & \\
\hline Positive & 141 & 17.20 & $13.06-21.34$ & & \\
\hline E-cadherin expression & & & & 3.685 & 0.055 \\
\hline Positive & 100 & 24.00 & $14.69-33.31$ & & \\
\hline Negative & 118 & 34.00 & $4.72-63.28$ & & \\
\hline
\end{tabular}

${ }^{\text {aS }}$ Significantly associated parameters. ${ }^{\mathrm{b} N a t i o n a l ~ C o m p r e h e n s i v e ~ C a n c e r ~ N e t w o r k ~ g u i d e l i n e s . ~ T N M, ~ t u m o r-n o d e-m e t a s t a s i s ; ~ Z E B 2, ~ z i n c ~ f i n g e r ~}$ E-box-binding homeobox 2; E-cadherin, epithelial cadherin.

Table VI. Multivariate Cox's regression analysis of overall survival in patients with esophageal squamous cell carcinoma.

\begin{tabular}{|c|c|c|c|c|c|}
\hline \multirow[b]{2}{*}{ Variables } & \multicolumn{5}{|c|}{ Multivariate analysis } \\
\hline & $\mathrm{B}$ & Wald & $\operatorname{Exp}(B)$ & $\begin{array}{c}\text { Hazard ratio } \\
\text { (95\% confidence } \\
\text { interval) }\end{array}$ & P-value \\
\hline Diameter (<4 vs. $\geq 4 \mathrm{~cm})$ & 0.346 & 3.836 & 1.414 & $1.000-1.999$ & 0.050 \\
\hline T statu) (positive vs. negative) & 0.853 & 11.776 & 2.346 & $1.441-3.817$ & $0.001^{\mathrm{a}}$ \\
\hline bTNM stage (I ands (22) (T1-T2 vs. T3-T4) & 0.455 & 0.264 & 1.576 & $0.094-2.572$ & 0.085 \\
\hline N status (22 II vs. III) & 0.338 & 3.839 & 1.402 & $1.000-1.965$ & 0.050 \\
\hline ZEB2 expression (positive vs. negative) & 0.450 & 5.707 & 1.568 & $1.084-2.269$ & $0.017^{\mathrm{a}}$ \\
\hline
\end{tabular}

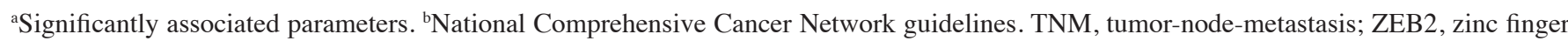
E-box-binding homeobox 2. 
types of cancer, including OSCC (29,34-36). Yoshida et al (30) reported increased ZEB2 expression in OSCC tissues compared with normal esophageal epithelium. ZEB2 controls the expression of matrix metalloproteinases (37) and other polarity proteins [protein crumbs homolog 3 and lethal (2) giant larvae protein homolog 2] (38) and therefore may be regarded as a master regulator of the EMT process (38).

In the present study, it was demonstrated that there was an association between the ZEB2 expression and a number of clinicopathological parameters, including depth of tumor invasion, lymph node metastasis and TNM stage. By contrast, negative expression of membrane E-cadherin was significantly associated with lymph node metastasis. Notably, there was no association between the ZEB2 or E-cadherin expression and the degree of tumor differentiation, although ZEB2 expression has been previously reported to be associated with histological differentiation in gastric cancer (39). Similar to the present study, ZEB2 overexpression in various tumors (pancreatic cancer, eyelid sebaceous gland, pharyngeal squamous cell and oral squamous cell carcinoma) has been significantly associated with node metastasis $(34,36,40,41)$, although another previous study reported no such association (42). The association between decreased E-cadherin expression and lymph node metastasis remains unclear, and whether these inconsistent findings can be accounted for by the different type of pathogenesis remains to be investigated $(43,44)$.

The survival rate of patients with positive ZEB2 expression was significantly decreased compared with patients with negative expression in univariate and multivariate analysis. ZEB2 expression was associated with invasion and metastatic characteristics, and the overall survival rate would be expected to be lower in patients with these characteristics. The findings of the present study are similar to those of previous studies, which reported that that ZEB2 is associated with poor prognosis in patients with ovarian, mammary gland, renal cell, head and neck, and gastric carcinoma $(35,45-48)$. In the present study, ZEB2 was an independent prognostic factor for shorter survival time in postoperative patients with OSCC, which is also in agreement with previous findings $(40,49,50)$.

It must be noted that, even though IHC techniques have become the focus of increasing attention, there remain a number of limitations. However, as the application of immunohistochemistry has increased, the estimated specificities to the antigens of the organ or tissue have remained comparable with some of the original expectations (51).

In summary, in the present study, it was demonstrated that ZEB2 and E-cadherin are frequently differentially expressed between OSCC and POT, and that ZEB2 and E-cadherin expression is associated with certain clinicopathological characteristics consistent with known biological function phenotypes. High ZEB2 expression in tumors is significantly and independently associated with poorer overall survival, particularly in patients with lymph node metastasis. Further studies are necessary to clarify the function of ZEB2 in EMT and to evaluate the prognostic significance of ZEB2.

\section{Acknowledgements}

The present study was supported by the National Natural Science Foundation of Tianjin (Tianjin, China) (grant no. 15JCYBJC28400) and the Science Foundation of Tianjin Medical University (Tianjin, China) (grant no. 2014KYQ27).

\section{References}

1. Xu Y, Yu X, Chen Q and Mao W: Neoadjuvant versus adjuvant treatment: Which one is better for resectable esophageal squamous cell carcinoma? World J Surg Oncol 10: 173, 2012.

2. Zhao P, Dai M, Chen W and Li N: Cancer trends in China. Jpn J Clin Oncol 40: 281-285, 2010.

3. Jemal A, Siegel R, Xu J and Ward E: Cancer statistics, 2010. CA Cancer J Clin 60: 277-300, 2010.

4. Song Y, Li L, Ou Y, Gao Z, Li E, Li X, Zhang W, Wang J, Xu L, Zhou Y, et al: Identification of genomic alterations in esophageal squamous cell cancer. Nature 509: 91-95, 2014.

5. Pennathur A, Gibson MK, Jobe BA and Luketich JD: Oesophageal carcinoma. Lancet 381: 400-412, 2013.

6. Rice TW, Rusch VW, Apperson-Hansen C, Allen MS, Chen LQ, Hunter JG, Kesler KA, Law S, Lerut TE, Reed CE, et al: Worldwide esophageal cancer collaboration. Dis Esophagus 22: $1-8,2009$

7. Shapiro IM, Cheng AW, Flytzanis NC, Balsamo M, Condeelis JS, Oktay MH, Burge CB and Gertler FB: An EMT-driven alternative splicing program occurs in human Breast Cancer and Modulates Cellular Phenotype. PLoS Genet 7: e1002218, 2011.

8. Polyak K and Weinberg RA: Transitions between epithelial and mesenchymal states: Acquisition of malignant and stem cell traits. Nat Rev Cancer 9: 265-273, 2009.

9. Peinado H, Olmeda D and Cano A: Snail, Zeb and bHLH factors in tumor progression: An alliance against the epithelial phenotype? Nat Rev Cancer 7: 415-428, 2007.

10. Niwa Y, Yamada S, Koike M, Kanda M, Fujii T, Nakayama G, Sugimoto H, Nomoto S, Fujiwara M and Kodera Y: Epithelial to mesenchymal transition correlates with tumor budding and predicts prognosis in esophagealsquamous cell carcinoma. J Surg Oncol 110: 764-769, 2014.

11. Jin H, Morohashi S, Sato F, Kudo Y, Akasaka H, Tsutsumi S, Ogasawara H, Miyamoto K, Wajima N, Kawasaki H, et al: Vimentin expression of esophageal squamous cell carcinoma and its aggressive potential for lymph node metastasis. Biomed Res 31: 105-112, 2010

12. Wang F, Li XK, Xu HY, Shan ZZ, Wang T, Yang ZC, He W, Wang LX and Fan QX: N-cadherin participated in invasion and metastasis of human esophageal squamous cell carcinoma via taking part in the formation of vasculogenic mimicry. Med Oncol 32: 480, 2015

13. Dong H, Xie L, Tang C, Chen S, Liu Q, Zhang Q, Zheng W, Zheng $\mathrm{Z}$ and Zhang H: Snaill correlates with patient outcomes in E-cadherin-preserved gastroesophageal junction adenocarcinoma. Clin Transl Oncol 16: 783-791, 2014.

14. Forghanifard MM, Moaven O, Farshchian M, Montazer M, Raeisossadati R, Abdollahi A, Moghbeli M, Nejadsattari T, Parivar K and Abbaszadegan MR: Expression analysis elucidates the roles of MAML1 and Twist 1 in esophageal squamous cell carcinoma aggressiveness and metastasis. Ann Surg Oncol 19: 743-749, 2012.

15. Gong T, Xue Z, Tang S, Zheng X, Xu G, Gao L, Zhao G, Hong L, Tang G, Zhang H, et al: Nuclear expression of Twist promotes lymphatic metastasis in esophageal squamous cell carcinoma. Cancer Biol Ther 13: 606-613, 2012.

16. Lee KW, Kim JH, Han S, Sung CO, Do IG, Ko YH, Um SH and $\mathrm{Kim} \mathrm{SH}$ : Twistl is an independent prognostic factor of esophageal squamous cell carcinoma and associated with its epithelial-mesenchymal transition. Ann Surg Oncol 19: 326-335, 2012.

17. Song X, Han P, Liu J, Wang Y, Li D, He J, Gong J, Li M, Tu W, Yan W, et al: Up-regulation of SPOCK1 induces epithelial-mesenchymal transition and promotes migration and invasion inesophageal squamous cell carcinoma. J Mol Histol 46: 347-356, 2015.

18. Wang N, Liu F, Cao F, Jia Y, Wang J, Ma W, Tan B, Wang K, Song Q and Cheng Y: RACK1 predicts poor prognosis and regulates progression of esophageal squamous cell carcinoma through its epithelial-mesenchymal transition. Cancer Biol Ther 16: 528-540, 2015.

19. Beck TN, Chikwem AJ, Solanki NR and Golemis EA: Bioinformatic approaches to augment study of epithelial-to-mesenchymal transition in lung cancer. Physiol Genomics 46: 699-724, 2014. 
20. Postigo AA, Depp JL, Taylor JJ and Kroll KL: Regulation of Smad signaling through a differential recruitment of coactivators and corepressors by ZEB proteins. EMBO J 22: 2453-2462, 2003.

21. Hegarty SV, Sullivan AM and O'Keeffe GW: Zeb2: A multifunctional regulator of nervous system development. Prog Neurobiol 132: 81-95, 2015

22. National Comprehensive Cancer Network. (NCCN) Clinical Practice Guidelines in Oncology.Esophageal and Esophagogastric Junction Cancers, version 1, 2015, https://www.nccn.org/professionals/physician_gls/f_guidelines.asp\#esophageal.

23. Hao XP, Pretlow TG, Rao JS and Pretlow TP: Beta-catenin expression is altered in human colonic aberrant crypt foci. Cancer Res 61: 8085-8088, 2001.

24. Jolly MK, Boareto M, Huang B, Jia D, Lu M, Ben-Jacob E, Onuchic JN and Levine $\mathrm{H}$ : Implications of the Hybrid Epithelial/Mesenchymal Phenotype in Metastasis. Front Oncol 5 $155,2015$.

25. Du HF, Ou LP, Yang X, Song XD, Fan YR, Tan B, Luo CL and

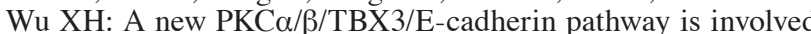
in PLCE-regulated invasion and migration in human bladder cancer cells. Cell Signal 26: 580-593, 2014.

26. Wu W, Tian Y, Wan H, Ma J, Song Y, Wang Y and Zhang L: Expression of $\beta$-catenin and $\mathrm{E}$ - and $\mathrm{N}$-cadherin in human brainstem gliomas and clinicopathological correlations. Int J Neurosci 123: 318-323, 2013.

27. Koay MH, Crook M and Stewart CJ: Cyclin D1, E-cadherin and beta-catenin expression in FIGO Stage IA cervical squamous carcinoma: Diagnostic value and evidence for epithelial-mesenchymal transition. Histopathology 61: 1125-1133, 2012.

28. Carneiro P, Figueiredo J, Bordeira-Carriço R, Fernandes MS, Carvalho J, Oliveira $\mathrm{C}$ and Seruca R: Therapeutic targets associated to E-cadherin dysfunction in gastric cancer. Expert Opin Ther Targets 17: 1187-1201, 2013.

29. Liu TA, Jan YJ, Ko BS, Liang SM, Chen SC, Wang J, Hsu C, Wu YM and Liou JY: 14-3-3e overexpression contributes to epithelial-mesenchymal transition of hepatocellular carcinoma. PLoS One 8: e57968, 2013.

30. Yoshida R, Morita M, Shoji F, Nakashima Y, Miura N, Yoshinaga K, Koga T, Tokunaga E, Saeki H, Oki E, et al: Clinical Significance of SIP1 and E-cadherin in Patients with Esophageal Squamous Cell Carcinoma. Ann Surg Oncol 22: 2608-2614, 2015.

31. Muir AB, Dods K, Noah Y, Toltzis S, Chandramouleeswaran PM Lee A, Benitez A, Bedenbaugh A, Falk GW, Wells RG, et al: Esophageal epithelial cells acquire functional characteristics of activated myofibroblasts after undergoing an epithelial to mesenchymal transition. Exp Cell Res 330: 102-110, 2015.

32. Fang WK, Liao LD, Zeng FM, Zhang PX, Wu JY, Shen J, Xu LY and Li EM: Desmocollin-2 affects the adhesive strength and cytoskeletal arrangement in esophageal squamous cell carcinoma cells. Mol Med Rep 10: 2358-2364, 2014

33. Wong TS, Gao W and Chan JY: Transcription regulation of E-cadherin by zinc finger E-box binding homeobox proteins in solid tumors. Biomed Res Int 2014: 921564, 2014.

34. Bhardwaj M, Sen S, Sharma A, Kashyap S, Chosdol K, Pushker N, Bajaj MS and Bakhshi S: ZEB2/SIP1 as novel prognostic indicator in eyelid sebaceous gland carcinoma. Hum Pathol 46: $1437-1442,2015$

35. Prislei S, Martinelli E, Zannoni GF, Petrillo M, Filippetti F, Mariani M, Mozzetti S, Raspaglio G, Scambia G and Ferlini C: Role and prognostic significance of the epithelial-mesenchymal transition factor ZEB2 in ovarian cancer. Oncotarget 6 : 18966-18979, 2015.

36. Galván JA, Zlobec I, Wartenberg M, Lugli A, Gloor B, Perren A and Karamitopoulou E: Expression of E-cadherin repressors SNAIL, ZEB1 and ZEB2 by tumor and stromal cells influences tumor-budding phenotype and suggests heterogeneity of stromal cells in pancreatic cancer. Br J Cancer 112: 1944-1950, 2015 .
37. Miyoshi A, Kitajima Y, Sumi K, Sato K, Hagiwara A, Koga Y and Miyazaki K: Snail and SIP1 increase cancer invasion by upregulating MMP family in hepatocellular carcinoma cells. $\mathrm{Br}$ J Cancer 90: 1265-1273, 2004.

38. Davalos V, Moutinho C, Villanueva A, Boque R, Silva P Carneiro $\mathrm{F}$ and Esteller M: Dynamic epigenetic regulation of the microRNA-200 family mediates epithelial and mesenchymal transitions in human tumorigenesis. Oncogene 31: 2062-2074, 2012.

39. Sun X, Sun Z, Zhu Z, Li C, Zhang J, Xu H and Sun M Expression of SIP1 is strongly correlated with LDHA and shows a significantly poor outcome in gastric cancer. Tumour Biol 36 7521-7530, 2015

40. Jouppila-Mättö A, Mannermaa A, Sironen R, Kosma VM, Soini Y and Pukkila M: SIP1 predicts progression and poor prognosis in pharyngeal squamous cell carcinoma. Histol Histopathol 30: 569-579, 2015.

41. Kong YH, Syed Zanaruddin SN, Lau SH, Ramanathan A, Kallarakkal TG, Vincent-Chong VK, Wan Mustafa WM, Abraham MT, Abdul Rahman ZA, Zain RB and Cheong SC: Co-Expression of TWIST1 and ZEB2 in oral squamous cell carcinoma is associated with poor Survival. PLoS One 10: e0134045, 2015

42. Miura N, Yano T, Shoji F, Kawano D, Takenaka T, Ito K, Morodomi Y, Yoshino I and Maehara Y: Clinicopathological significance of Sipl-associated epithelial mesenchymal transition in non-small cell lung cancer progression. Anticancer Res 29: 4099-4106, 2009.

43. Mehendiratta M, Solomon MC, Boaz K, Guddattu V and Mohindra A: Clinico-pathological correlation of Ecadherin expression at the invasive tumor front of Indian oral squamous cell carcinomas: An immunohistochemical study. J Oral Maxillofac Pathol 18: 217-222, 2014.

44. Mostaan LV, Khorsandi MT, Sharifian SM, Shandiz FH, Mirashrafi F, Sabzari H, Badiee R, Borghei H and Yazdani N: Correlation between E-cadherin and CD44 adhesion molecules expression and cervical lymph node metastasis in oral tongue SCC: Predictive significance or not. Pathol Res Pract 207: 448-451, 2011.

45. Gamba CO, Campos LC, Negreiros-Lima GL, Maciel-Lima K, Sousa LP, Estrela-Lima A, Ferreira E and Cassali GD: ZEB2 and ZEB1 expression in a spontaneous canine model of invasive micropapillary carcinoma of the mammary gland. Res Vet Sci 97: 554-559, 2014

46. Fang Y, Wei J, Cao J, Zhao H, Liao B, Qiu S, Wang D, Luo J and Chen W: Protein expression of ZEB2 in renal cell carcinoma and its prognostic significance in patient survival. PLoS One 8: e62558, 2013

47. Chu PY, Hu FW, Yu CC, Tsai LL, Yu CH, Wu BC, Chen YW, Huang PI and Lo WL: Epithelial-mesenchymal transition transcription factor ZEB1/ZEB2 co-expression predicts poor prognosis and maintains tumor-initiating properties in head and neck cancer. Oral Oncol 49: 34-41, 2013.

48. Okugawa Y, Inoue Y, Tanaka K, Kawamura M, Saigusa S, Toiyama Y, Ohi M, Uchida K, Mohri Y and Kusunoki M: Smad interacting protein 1 (SIP1) is associated with peritoneal carcinomatosis in intestinal type gastric cancer. Clin Exp Metastasis 30: 417-429, 2013.

49. Sayan AE, Griffiths TR, Pal R, Browne GJ, Ruddick A, Yagci T, Edwards R, Mayer NJ, Qazi H, Goyal S, et al: SIP1 protein protects cells from DNA damage-induced apoptosis and has independent prognostic value in bladder cancer. Proc Natl Acad Sci USA 106: 14884-14889, 2009.

50. Maeda G, Chiba T, Okazaki M, Satoh T, Taya Y, Aoba T, Kato K, Kawashiri S and Imai K: Expression of SIP1 in oral squamous cell carcinomas: Implications for E-cadherin expression and tumor progression. Int J Oncol 27: 1535-1541, 2005.

51. Torlakovic EE, Nielsen S, Vyberg M and Taylor CR: Getting controls under control: The time is now for immunohistochemistry. J Clin Pathol 68: 879-882, 2015. 